OPEN ACCESS

Edited by:

Xiao-Wei Wen,

South China Agricultural University,

China

Reviewed by:

Rui Li,

Foshan University, China Imran Khan,

Prince Sultan University, Saudi Arabia

${ }^{*}$ Correspondence:

Din Jong

djong@mail.hwai.edu.tw;

hi1212@gmail.com

Specialty section:

This article was submitted to

Organizational Psychology,

a section of the journa

Frontiers in Psychology

Received: 02 July 2020 Accepted: 22 September 2020

Published: 05 November 2020

Citation:

You J-J, Jong D and Wiangin U (2020) Consumers' Purchase Intention of Organic Food via Social

Media: The Perspectives

of Task-Technology Fit

and Post-acceptance Model.

Front. Psychol. 11:579274.

doi: 10.3389/fpsyg.2020.579274

\section{Consumers' Purchase Intention of Organic Food via Social Media: The Perspectives of Task-Technology Fit and Post-acceptance Model}

\author{
Jun-Jer You ${ }^{1}$, Din Jong ${ }^{2 *}$ and Uraiporn Wiangin ${ }^{3}$ \\ ${ }^{1}$ Department of Exercise and Health Sciences, University of Taipei, Taipei, Taiwan, ${ }^{2}$ Department of Digital Design \\ and Information Management, Chung Hwa University of Medical Technology, Tainan City, Taiwan, ${ }^{3}$ Department of Business \\ Administration, Ramkhamhaeng University, Bangkok, Thailand
}

In the past, consumers were mainly informed about organic food by newspapers, magazines, and television advertisements. However, when consumers buy organic products in the market, they cannot get a complete information about the products from the appearance of the various products. In order to overcome this information asymmetry, social media has become an indispensable part of the promotion of organic food by providing a clear distinction between certified organic products and other types of products in the market. The purpose of this study is to demonstrate the antecedents and consequences of the influence of social media on the consumers' selection of organic food, based on the post-acceptance model (PAM) and tasktechnology fit model. The empirical results indicated task characteristics and technology characteristics had the significant effects on confirmation of the expectations and perceived usefulness through the task-technology fit. Besides, the confirmation of expectations and perceived usefulness also influenced significantly the satisfaction and continuance intention, respectively. Finally, the results presented in this article would contribute to the practical and academic implications and recommendations on the promotion of organic food in the social media platform.

Keywords: organic food, social media, task-technology fit, post-acceptance model, partial least squares

\section{INTRODUCTION}

For a long time, with the advancement of technology and commercial development, food products have been genetically modified and chemically processed from cultivation to mass production in order to pursue economic benefits while neglecting the potential harm to humans and the environment. As a result, the rise of the consumers' concept of health and wellness, coupled with the demand for the concept of safe and nontoxic food, has increased the acceptance of organic food, and organic food is gradually becoming a dietary trend (Michaelidou and Hassan, 2008; Benbrook and Baker, 2014; Ronald and Adamchak, 2017). Currently, organic food is a concept and a trend, in addition to the appeal of natural and healthy diet, but it also does not damage the natural environment (farmland, soil, and water), pay attention to the ecology, in order to achieve the principle of symbiotic sustainability between man and nature.

In the past, consumers were mainly informed about organic food by newspapers, magazines, and TV advertisements, and the main motivation for buying organic food is that they feel it is healthier for their health. The value of an organic product lies in the process of production 
and manufacturing to the point where the final product complies with stringent organic regulations; however, when consumers purchase organic products in the market, they do not get the complete picture from the appearance of the product (Janssen and Hamm, 2012). In addition to its penetration and pervasiveness, social media is also efficient in gathering users of the same type or background (Allagui and Breslow, 2016). According to Palen (2008), survivors of social disasters or victims of major crises are often able to use social media to find others with similar experiences, to share their experiences, and to generate the support and connections that are characteristics of a victim's community.

Many prior research on social media has been conducted from a technology-acceptance perspective, discussing antecedents and consequences (Chen et al., 2012; Rauniar et al., 2014; Ayeh, 2015; Lin and Kim, 2016; Wamba et al., 2017; Zhao and Wang, 2020). However, the above research results only concentrated on the correlation between the IT and individual usage behavior, and these studies provided a little discussion on how social media influences consumer adoption or purchase intention of organic food. Through this study, we can understand the important factors through which consumers adopt social media to receive messages about organic food. In order to overcome this information asymmetry, social media is playing an important role in the promotion of organic food by clearly separating certified organic products from other types of products in the market and enabling the consumers to identify the labels of certified organic products. At the same time, the transparency of organic food information will increase the consumption of organic food. Therefore, this study devoted effort for developing an integrated model designed to explain and predict the consumers' purchase intention of organic food based on the concepts of the post-acceptance model (PAM) by Bhattacherjee (2001) and the task-technology fit (TTF) model by Goodhue and Thompson (1995). In addition, previous empirical studies on the impact of organic food purchasing intentions in the past were based on the pre-consumer attitude toward organic food (e.g., Yin et al., 2010; Paul and Rana, 2012; Basha et al., 2015; Singh and Verma, 2017). Therefore, the purpose of this study is to demonstrate the antecedents (three antecedents including task characteristics, technology, and tasktechnology fit, and two factors including the confirmation of expectations and perceived usefulness) and consequences (two factors including the satisfaction and continuance intention toward organic food social media platform) of the influence of social media on the consumers' selection of organic food based on the PAM and TTF model using a partial least square (PLS) approach.

\section{THEORETICAL BACKGROUND}

\section{Post-acceptance Model}

The expectation confirmation theory (ECT), proposed by Oliver and Richard (1980) and originated in the field of marketing, is based on the concept that (1) consumers had a certain level of expectation for a particular product (or service) before they buy it; (2) after the consumer had experienced the product (or service) for some time, he/she develops a new awareness of the performance that the product (or service) brings; (3) Then, the consumers will compare the perceived performance after experiencing the product (or service) with their initial expectations in order to assess the consistency (i.e., the degree of confirmation); (4) The results of the comparison will affect the level of satisfaction, and the level of satisfaction will affect the likelihood of repurchase or reuse. ECT was extensively used to evaluate consumer satisfaction and behavior after purchase (e.g., repeated purchase and complaint) as well as general service marketing in a past literature review of consumer behavior research (Oliver and Richard, 1980; Tse and Wilton, 1988; Anderson and Sullivan, 1993; Oliver, 1993; Patterson et al., 1997; Dabholkar et al., 2000).

Bhattacherjee (2001) argued that (1) an information system user's ongoing adoption decision is similar to a consumer's repurchase decision behavior; (2) affected by the first experience (information system or product); and (3) may eventually reverse the initial decision. Bhattacherjee (2001) argued that the past ECT was somewhat controversial and irrational, and took into account the need to effectively predict and explain the continuous adoption behavior of information system users. Bhattacherjee (2001) modified ECT one by one to make it conform to the use of information systems and proposed the PAM of IS continuance, the main points of which are as follows: (1) PAM focuses on the adoption of the postacceptance variable because the impact of the adoption of the preacceptance variable is covered by the concepts of confirmation and satisfaction. (2) The original ECT only investigated the preconsumption expectation, but the users' expectations changed over time, so the postconsumption expectation was especially emphasized in the continued adoption model after the IS acceptance. (3) In the IS acceptance PAM, the post-experience expectations are interpreted as perceived usefulness, a concept consistent with the expectations defined by ECT (i.e., the set of personal beliefs or interbeliefs), and perceived usefulness appropriately represents a user's significant cognitive beliefs about the information system (Davis, 1989). In recent years, although scholars have been using the PAM to explain the continued adoption of various innovative technologies (e.g., Roca et al., 2006; Bhattacherjee et al., 2008; Chen et al., 2013, 2018; Oghuma et al., 2016; Park, 2020), little is known about the determinants affecting the consumers' usage intention and evaluation of social media platform to gather relevant information of organic food. Social media operators, which provided and promoted the organic food information should think how to gain rapid acceptance and usage of social media by potential users or consumers. Therefore, this study applied PAM as the basis and extended it to assist social media operators to predict and explain the acceptance of social media platform toward organic foods.

\section{Task-Technology Fit}

Goodhue and Thompson (1995) distinguished the job characteristics in terms of non-routineness and interdependence. Among them, a high level of routine indicates that this type of 
problem is more likely to be a simple or problematic task. When such tasks are not routine, they tend to be decision-making tasks, judgmental tasks, or vague tasks where the degree of interdependence refers to whether the task can be completed alone or requires the assistance of other departments or other personnel. Tasks with a low level of interdependence may be simple or problematic. Tasks with a high level of interdependence may be problematic, decision making, judgmental, or ambiguous.

The task-technology fit theory proposed by Goodhue and Thompson (1995) emphasizes the impact of technology on individual performance, which is the result of the fit between task, technology, and individual, and an ideal fit can effectively enhance performance. Dishaw and Strong (1999) first attempted to extend task-technology fit and showed that this integration model improved the ability of the model to interpret information technology use. Relevant studies regarding task-technology fit is implemented after Dishaw and Strong (1999) presented the extension of task-technology fit. Klopping and McKinney (2004) studied the propensity and actual purchase behavior of online shopping using an integrated TTF extended TAM model, and the results showed that the degree of interpretable variation of the integrated model was higher than that of the simple TAM model. Larsen et al. (2009) explored information systems through the integration model of the TTF and ECM-the user's related behavior. Chang (2010) applied the integrated models of a task-technology fit into TAM to evaluate the users' acceptance of online auctions. Khan et al. (2018) developed an integrated model including the task-technology fit, social motivation, and self-determination theory to represent the technology-oriented, social, and psychological needs of learners regarding the adoption of massive open online courses (MOOCs) in Pakistan.

Therefore, according to the above discussion, the tasktechnology fit could improve the shortcomings of the PAM and allow this study to take into account the other more relevant factors that influence the consumers' willingness to purchase organic food through social media.

\section{HYPOTHESES DEVELOPMENT AND RESEARCH METHODOLOGY}

\section{Research Hypotheses Development}

Task-technology fit, defined as how the capabilities of the infrastructure such as information systems match the tasks that the users must perform, is a key determinant in explaining performance levels (Goodhue et al., 2000). The model of task technology, developed by Goodhue and Thompson (1995), has been adopted in various information system/information technology acceptance research (Schrier et al., 2010; Yen et al., 2010; Lu and Yang, 2014; Khan et al., 2018), and it focuses on the matching of the technology to the task, thereby increasing the individual performance (Goodhue et al., 2000). Therefore, we hypothesize the following:

H1: Task characteristics positively affect the perceived tasktechnology fit in an organic food social media forum.
H2: Technology characteristics positively affect the perceived task-technology fit in an organic food social media forum.

Previous research believed that the perception of whether a particular task-technology fits well with the perceived usefulness could be the basis for constructing perceptions of actually adopting the information technologies (Kim et al., 2010; Wu and Chen, 2017). Empirical evidence has illustrated that the perceived usefulness is affected by the task-technology fit; that is, when the fit between the task and technology is higher, consumers perceive the digital tool to be useful for that task (Larsen et al., 2009; Chang, 2010; Schrier et al., 2010; Lin and Wang, 2012; Wu and Chen, 2017). Moreover, the empirical result from Cheng (2020) also found the positive linage from the tasktechnology fit to confirmation. Thus, we proposed the following two research hypotheses:

H3: Perceived task-technology fit positively affects the perceived usefulness in an organic food social media forum.

H4: Perceived task-technology fit positively affects the confirmation in an organic food social media forum.

Satisfaction is critical to promote the successful implementation toward information systems/information technologies (Au et al., 2008). Therefore, satisfaction plays a critical role in PAM (Bhattacherjee, 2001; Chen et al., 2013, 2018). Prior research evidently supported the confirmation of expectations and perceived usefulness continuance intention through satisfaction toward various digital and mobile services (Lin et al., 2005; Chen et al., 2013; Oghuma et al., 2016; Park, 2020; Tam et al., 2020). According to the above evidence, a summary of research hypotheses related to PAM and intention to use social media in gathering organic food information environment are presented as follows:.

H5: Confirmation positively affects the perceived usefulness in an organic food social media forum.

H6: Perceived usefulness positively affects the continuance intention in an organic food social media forum.

H7: Perceived usefulness positively affects the satisfaction in an organic food social media forum.

H8: Confirmation positively affects the satisfaction in an organic food social media forum.

H9: Satisfaction positively affects the continuance intention in an organic food social media forum.

\section{Research Methodology}

Considering the above nine hypotheses, we designed a questionnaire to measure and understand the users' perceptions in the organic food social media forum. For content validity, all the measurement items for each latent variable in the questionnaire were from existing studies. PAM, including the continuance intention, satisfaction, perceived usefulness, and 
confirmation, were adopted from Bhattacherjee (2001) and Chen et al. (2013). The concept of the task-technology fit, including the technology characteristics and task characteristics, were slightly modified from Chang (2010) and Wu and Chen (2017). Each measurement item was replied following the seven-point Likert's scale. For example, range from 1, "strongly disagreement" to 7 , "strongly agreement."

In this study, the partial least squares (PLSs) is used as the data analysis tool for the research model. The PLS is a structural equation modeling (SEM) analysis technique based on a regression analysis, which is a statistical method derived from the path analysis. By using PLS analysis, both the measurement model of the research tool and the structural model of the research component can be examined. Past research has shown that PLS can evaluate both the measured model and the theoretical structural model and is, therefore, superior to the traditional regression analysis and factor analysis methods (Urbach and Ahlemann, 2010; Hair et al., 2012; Henseler et al., 2015). In addition, compared with the LISREL method commonly used in the academia, PLS requires a smaller sample size for analysis, and the observational data is not available. PLS requires multivariate constant assumptions and is better at prediction. Model flexibility is also greater (Ringle et al., 2012). PLS analysis software used in this study is the SmartPLS (version 3.3.2) and uses bootstrap resampling method to check the significance of the paths in the structural model. The research hypotheses of this research are shown in Table 1, and the research framework is shown in Figure 1.

A questionnaire survey was used to collect data by convenience sampling method, and questionnaires were collected from four organic food promotion Facebook communities. To ensure the content validity, all samples had relevant experience in participating in organic food discussions or purchasing behavior through social media. The sample recall period was 4 weeks. The total number of samples collected was 284 . After data checking and deletion of invalid questionnaires, the remaining number of valid samples was 235 . Among them, $41.2 \%$ were male and $58.8 \%$ were female. Sixty-two percent $(60.2 \%)$ of the samples had university education, and most of them (72.6\%) were aged 26 to 40 years old.

\section{DATA ANALYSIS}

\section{Outer Model}

In order to further examine the reliability and validity of the scale questionnaire, this study uses the PLS statistical software to check the appropriateness of the measurement model. The validation of

TABLE 1 | Research hypotheses.

\begin{tabular}{|c|c|}
\hline Hypothesis & Hypothesis statement \\
\hline Hypothesis 1 & Task characteristics positively affect the perceived task-technology fit in an organic food social media forum. \\
\hline Hypothesis 2 & Technology characteristics positively affect the perceived task-technology fit in an organic food social media forum. \\
\hline Hypothesis 3 & Perceived task-technology fit positively affects the perceived usefulness in an organic food social media forum. \\
\hline Hypothesis 4 & Perceived task-technology fit positively affects the confirmation in an organic food social media forum. \\
\hline Hypothesis 5 & Confirmation positively affects the perceived usefulness in an organic food social media forum. \\
\hline Hypothesis 6 & Perceived usefulness positively affects the continuance intention in an organic food social media forum. \\
\hline Hypothesis 7 & Perceived usefulness positively affects the satisfaction in an organic food social media forum. \\
\hline Hypothesis 8 & Confirmation positively affects the satisfaction in an organic food social media forum. \\
\hline Hypothesis 9 & Satisfaction positively affects the continuance intention in an organic food social media forum. \\
\hline
\end{tabular}

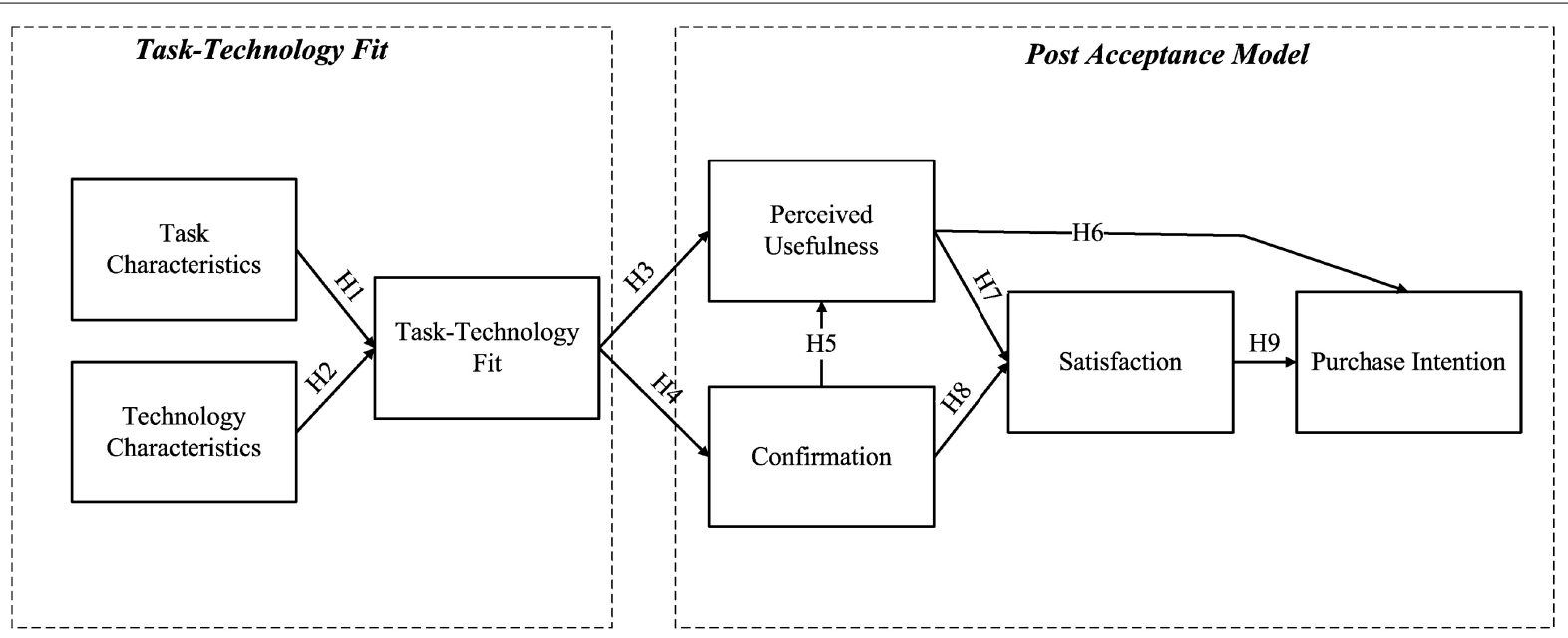

FIGURE 1 | Integration model of task-technology fit (TTF) and post-acceptance model (PAM). 
the measurement model includes checks for internal consistency, convergent validity, and discriminate validity. Reliability is the correctness and accuracy of a measurement tool, which has two meanings. Stability is the degree of reliability of retesting and consistency is the measurement of the internal consistency among the items in the questionnaire. This study adopts the composite confidence level of the least square method (PLS). Reliability was analyzed with the Cronbach's $\alpha$ and composite reliability. According to Fornell and Larcker (1981), the composite reliability (CR) and Cronbach's $\alpha$ should be above 0.7 to ensure that the measurement variables are internally consistent. While the $\mathrm{CR}$ values in this study were all above 0.880 (as shown in Table 1), the Cronbach's $\alpha$ values were all above 0.728 and above, indicating that the internal consistency of the measurement tools designed in this study is acceptable.

Convergent validity indicates the degree to which multiple variables measure the same dimension. According to the suggestion of Fornell and Larcker (1981), the average variance extracted (AVE) for each individual component must be greater than 0.5 , and the factor loadings of each component must be greater than 0.5 (Hair et al., 2010). The factor loadings of each component must be greater than 0.5 to be considered as having sufficient convergent validity. The AVE values of each structure are above 0.699 (as shown in Table 2). According to the above analysis, it means that the measurement model in this study passes the test and satisfies the need for the convergent validity (as shown in Table 2).

The discriminant validity is to check how well the measurement variables discriminate between the different configurations. The correlation between each variable and other variables of the same dimension should be higher than the correlation between the variables of the different dimensions. In order to pass the test of discriminant validity, the square root of AVE from an individual component should be greater than the correlation coefficient (non-diagonal value) between that component and the other components in the model to indicate the discriminant validity (Fornell and Larcker, 1981). Table 3 shows the matrix of correlation coefficients between each component, and the diagonal lines are the square roots of the AVE of that component. Table 3 shows that the square roots of the AVEs for each of the structural measurement items are larger than the correlation coefficients between the two components,

\begin{tabular}{lccc}
\multicolumn{3}{l}{ TABLE 2 | Reliability and convergent validity. } & \\
\hline Construct & Cronbach's alpha & Composite reliability & AVE \\
\hline Cl & 0.890 & 0.932 & 0.821 \\
CON & 0.919 & 0.943 & 0.804 \\
PU & 0.901 & 0.931 & 0.771 \\
SAT & 0.935 & 0.959 & 0.885 \\
TASK & 0.846 & 0.907 & 0.764 \\
TECH & 0.857 & 0.903 & 0.699 \\
TTF & 0.728 & 0.880 & 0.786 \\
\hline
\end{tabular}

AVE, average variance extracted. $\mathrm{Cl}$, continuance intention; CON, confirmation; PU, perceived usefulness; SAT, satisfaction; TASK, task characteristics; TECH, technology characteristics; TTF, Task Technology fit.
TABLE 3 | Correlations and discriminant validity.

\begin{tabular}{lccccccr}
\hline Construct & Cl & CON & PU & SAT & TASK & TECH & TTF \\
\hline CI & $\mathbf{0 . 9 0 6}$ & & & & & & \\
CON & 0.734 & $\mathbf{0 . 8 9 7}$ & & & & & \\
PU & 0.558 & 0.680 & $\mathbf{0 . 8 7 8}$ & & & & \\
SAT & 0.714 & 0.835 & 0.598 & $\mathbf{0 . 9 4 1}$ & & & \\
TASK & 0.546 & 0.601 & 0.625 & 0.640 & $\mathbf{0 . 8 7 4}$ & & \\
TECH & 0.527 & 0.575 & 0.474 & 0.610 & 0.666 & $\mathbf{0 . 8 3 6}$ & \\
TTF & 0.523 & 0.582 & 0.618 & 0.557 & 0.659 & 0.537 & $\mathbf{0 . 8 8 7}$
\end{tabular}

Cl, continuance intention; CON, confirmation; PU, perceived usefulness; SAT, satisfaction; TASK, task characteristics; TECH, technology characteristics; TTF, task technology fit. The diagonal value represents the square root of the AVE. The nondiagonal value represents the correlation value of each component. The bold values means the square roots of the AVE.

which means that the questions of different components in the questionnaire of this study can be discriminated adequately. In addition, by comparing the factor loadings and cross loadings within each study construct, it can also be seen that this study has a good discriminant validity (as shown in Table 4).

\section{Inner Model}

In this study, PLS is used as an analytical tool to analyze the strength and direction of the relationship between the study variables in the structural model. The structural model

TABLE 4 | Factor loadings and cross loadings.

\begin{tabular}{lccccccc}
\hline & Cl & CON & PU & SAT & TASK & TECH & TTF \\
\hline Cl1 & $\mathbf{0 . 9 2 7}$ & 0.643 & 0.541 & 0.635 & 0.480 & 0.463 & 0.445 \\
Cl2 & $\mathbf{0 . 9 3 9}$ & 0.656 & 0.545 & 0.616 & 0.495 & 0.425 & 0.477 \\
Cl3 & $\mathbf{0 . 8 4 9}$ & 0.693 & 0.430 & 0.686 & 0.507 & 0.540 & 0.496 \\
CON1 & 0.627 & $\mathbf{0 . 8 9 2}$ & 0.606 & 0.695 & 0.511 & 0.524 & 0.478 \\
CON2 & 0.643 & $\mathbf{0 . 9 0 5}$ & 0.598 & 0.710 & 0.514 & 0.512 & 0.531 \\
CON3 & 0.620 & $\mathbf{0 . 8 9 2}$ & 0.628 & 0.807 & 0.544 & 0.491 & 0.489 \\
CON4 & 0.738 & $\mathbf{0 . 8 9 8}$ & 0.606 & 0.777 & 0.583 & 0.536 & 0.585 \\
PU1 & 0.482 & 0.529 & $\mathbf{0 . 8 3 9}$ & 0.445 & 0.515 & 0.385 & 0.544 \\
PU2 & 0.429 & 0.551 & $\mathbf{0 . 8 8 5}$ & 0.482 & 0.560 & 0.383 & 0.597 \\
PU3 & 0.475 & 0.622 & $\mathbf{0 . 9 2 1}$ & 0.543 & 0.565 & 0.445 & 0.572 \\
PU4 & 0.563 & 0.671 & $\mathbf{0 . 8 6 5}$ & 0.612 & 0.553 & 0.446 & 0.468 \\
SAT1 & 0.639 & 0.734 & 0.525 & $\mathbf{0 . 9 2 1}$ & 0.571 & 0.519 & 0.482 \\
SAT2 & 0.680 & 0.794 & 0.579 & $\mathbf{0 . 9 6 3}$ & 0.615 & 0.593 & 0.545 \\
SAT3 & 0.695 & 0.826 & 0.581 & $\mathbf{0 . 9 3 8}$ & 0.619 & 0.605 & 0.542 \\
TASK1 & 0.509 & 0.520 & 0.584 & 0.569 & $\mathbf{0 . 8 7 9}$ & 0.570 & 0.614 \\
TASK2 & 0.480 & 0.573 & 0.563 & 0.592 & $\mathbf{0 . 8 8 7}$ & 0.586 & 0.526 \\
TASK3 & 0.440 & 0.488 & 0.490 & 0.520 & $\mathbf{0 . 8 5 6}$ & 0.592 & 0.581 \\
TECH1 & 0.479 & 0.473 & 0.424 & 0.486 & 0.560 & $\mathbf{0 . 8 0 6}$ & 0.526 \\
TECH2 & 0.320 & 0.348 & 0.316 & 0.404 & 0.473 & $\mathbf{0 . 8 2 7}$ & 0.336 \\
TECH3 & 0.457 & 0.514 & 0.378 & 0.523 & 0.538 & $\mathbf{0 . 8 9 4}$ & 0.417 \\
TECH4 & 0.463 & 0.550 & 0.435 & 0.595 & 0.624 & $\mathbf{0 . 8 1 4}$ & 0.467 \\
TF1 & 0.458 & 0.525 & 0.541 & 0.497 & 0.630 & 0.488 & $\mathbf{0 . 8 9 3}$ \\
TF2 & 0.469 & 0.507 & 0.555 & 0.491 & 0.537 & 0.464 & $\mathbf{0 . 8 8 0}$ \\
\hline Cl C0nth & & & & & & & \\
\hline
\end{tabular}

$\mathrm{Cl}$, continuance intention; CON, confirmation; $\mathrm{PU}$, perceived usefulness; SAT, satisfaction; TASK, task characteristics; TECH, technology characteristics; TTF, task technology fit. The bold values means standardized factor loadings. 


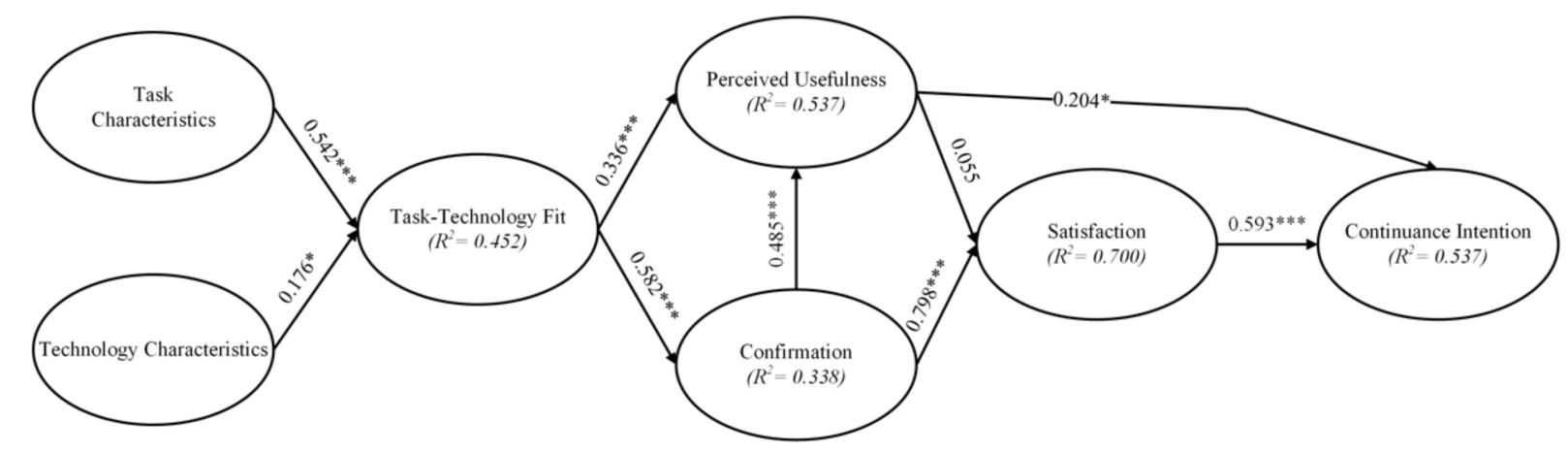

FIGURE 2 | Inner model.

TABLE 5 | Inner model and path analysis.

\begin{tabular}{lcccc}
\hline & $\begin{array}{c}\text { Original } \\
\text { sample (O) }\end{array}$ & $\begin{array}{c}\text { Standard } \\
\text { deviation } \\
\text { (STDEV) }\end{array}$ & $\begin{array}{c}\boldsymbol{T} \\
\text { Statistics } \\
\text { (|O/STDEV|) }\end{array}$ & P-values \\
\hline $\mathrm{H} 1: \mathrm{TASK} \rightarrow$ TTF & 0.542 & 0.080 & 6.747 & 0.000 \\
$\mathrm{H} 2: \mathrm{TECH} \rightarrow$ TTF & 0.176 & 0.082 & 2.154 & 0.031 \\
$\mathrm{H} 3: \mathrm{TTF} \rightarrow \mathrm{PU}$ & 0.336 & 0.079 & 4.262 & 0.000 \\
$\mathrm{H} 4: \mathrm{TTF} \rightarrow \mathrm{CON}$ & 0.582 & 0.060 & 9.690 & 0.000 \\
$\mathrm{H} 5: \mathrm{CON} \rightarrow \mathrm{PU}$ & 0.485 & 0.083 & 5.858 & 0.000 \\
$\mathrm{H} 6: \mathrm{PU} \rightarrow \mathrm{Cl}$ & 0.204 & 0.083 & 2.462 & 0.014 \\
$\mathrm{H} 7: \mathrm{PU} \rightarrow \mathrm{SAT}$ & 0.055 & 0.068 & 0.807 & 0.420 \\
$\mathrm{H} 8: \mathrm{CON} \rightarrow$ SAT & 0.798 & 0.058 & 13.839 & 0.000 \\
$\mathrm{H} 9: \mathrm{SAT} \rightarrow \mathrm{Cl}$ & 0.593 & 0.067 & 8.828 & 0.000
\end{tabular}

Cl, continuance intention; CON, confirmation; PU, perceived usefulness; SAT, satisfaction; TASK, task characteristics; TECH, technology characteristics; TTF, task technology fit.

is validated mainly in terms of the estimated path coefficients and $R$-values. The coefficient of path represents the strength and direction of the relationship between the study variables and should be verified as significant and consistent with the expected direction of the hypothesis. The $R$-value is the percentage of variation explained by the exogenous variables versus the endogenous variables and represents the predictive power of the research model. The path coefficients and $R$-values together show how well the structural model and data fit together. The results of the analysis of the structural model of this study are shown in Figure 2 and Table 5.

Each component affects the part of the persistent use of intention, including the perceived usefulness $(\beta=0.204$, $p<0.014)$ and satisfaction $(\beta=0.593, p<0.001)$; both of these two constructs have a significant effect on the persistence of the intention. The effect of partial confirmation of the satisfaction ( $\beta=0.798, p<0.001)$ on the satisfaction was significant, but the perceived usefulness was not. The effect of $\beta(\beta=0.055$, $p=0.420)$ on the satisfaction was not significant. In the section on the perceived usefulness of each component, the confirmation $(\beta=0.485, p<0.001)$ and task-technology fitness $(\beta=0.336$, $p<0.001$ ), both components had a significant effect on the perceived usefulness. Task-technology fit $(\beta=0.582, p<0.001)$ has a significant effect on the degree of recognition. Finally, in the component of task-technology fitness for each construct, the task characteristics $(\beta=0.542, p<0.001)$ and technology characteristics $(\beta=0.176, p<0.05)$, the effect of the tasktechnology fit is significant for both structures.

\section{DISCUSSION AND CONCLUSION}

The study contributes to the theoretical assessment by integrating PAM and TTF as the research framework to investigate the factors that influence the consumers' adoption of organic food information through social media. Our study adopted the PAM presented by Bhattacherjee (2001) as the framework basis, adds TTF as the external variable, and establishes a research framework to understand the influence of PAM on the consumers' purchase intention toward organic food via social media. This framework analyzes the factors when the users use cloud computing services, such as TTF, perceived usefulness, confirmation, satisfaction, and continuance intention, to assess the influence of TTF on the continuance intention. After that, the data were collected through questionnaires, and the model was validated using the PLS method, and many significant findings were obtained. Compared with the individual TTF and PAM models, the integrated model provides more explanation power on the consumers' adoption toward an organic food social media platform. The proposed model of this study provides more precise results than the PAM and TTF model do separately, and the extended model assists practitioners and scholars in understanding the dynamics of organic food information toward social media platform.

The purpose of this survey was to understand and validate the proposed model of integrating PAM and TTF to assess the influencers of the consumers' continuance intention to gather the information regarding organic food in social media environment. Important findings were outlined as follows. First, as theorized by TTF, both task characteristics and technology characteristics significantly influence the tasktechnology fit. TTF, by itself, is also a robust model in which the task and technology characteristics significantly determine the correspondence between information acquisition of 
organic food (i.e., task requirements) and technology functionality of social media platform. In addition, the task characteristics were found to be more influential than the technology characteristics. By decomposing TTF, we offer relevant perspectives as to which task and technology dimension becomes critical in the consumers' acceptance decisions for the organic food social media platform. Second, for the PAM model, except for the perceived usefulness to satisfaction, the other four paths-the perceived usefulness and satisfaction to continuance intention, the confirmation to perceived usefulness and satisfaction-have positive and significant impacts. Because satisfaction is the most critical determinants of the continuance intention (explaining $70 \%$ of variance) relative to the other determinants, the consumers dissatisfied with an organic food social media platform may stop using it, despite having positive perceptions with regard to other factors. Third, we also found that there exists correlations between the TTF and PAM ones (i.e., confirmation of expectations and perceived usefulness). In recent years, due to changes in dietary patterns, the number of people eating out has increased, resulting in many health problems caused by excessive and unbalanced diets. In addition, the pesticides and chemicals used by farmers in the past to grow crops with beautiful appearance and integrity have seriously contaminated the soil, water, and air, leaving a large amount of harmful substances on the surface of the crops or inside the organisms, which can cause diseases. Therefore, understanding how to find and promote organic food information and food safety through social media is an important issue in the relevant research area. All countries have strict organic product labeling regulations and state that only products that comply with national organic regulations can be sold with organic labels or organic names, and prohibit other products that do not comply with organic regulations from using labels that mislead consumers into thinking that the product is organic.

\section{RESEARCH LIMITATIONS AND FUTURE WORK}

This study strives to be rigorous, objective, and thorough in its process and analysis in order to obtain good research results.

\section{REFERENCES}

Allagui, I., and Breslow, H. (2016). Social media for public relations: lessons from four effective cases. Public Relat. Rev. 42, 20-30. doi: 10.1016/j.pubrev.2015.12. 001

Anderson, E. W., and Sullivan, M. W. (1993). The antecedents and consequences of customer satisfaction for firms. Mark. Sci. 12, 125-143. doi: 10.1287/mksc. 12.2.125

Au, N., Ngai, E. W., and Cheng, T. E. (2008). Extending the understanding of end user information systems satisfaction formation: an equitable needs fulfillment model approach. MIS Q. 32, 43-66. doi: 10.2307/25148828

Ayeh, J. K. (2015). Travellers' acceptance of consumer-generated media: an integrated model of technology acceptance and source credibility theories. Comput. Hum. Behav. 48, 173-180. doi: 10.1016/j.chb.2014.12.049

Basha, M. B., Mason, C., Shamsudin, M. F., Hussain, H. I., and Salem, M. A. (2015). Consumers attitude towards organic food. Procedia Econ. Finance 31, 444-452. doi: 10.1016/s2212-5671(15)01219-8
However, due to time, manpower, and environment-related factors, there are still the following research limitations. First, the sample of this study was drawn from consumers who purchased organic food through social media, which was sufficient to ensure the content validity. However, in the future, it is recommended that a consumer segmentation analysis should be conducted on different ethnic groups, consumption patterns, and habits in order to better understand the pre-purchase factors of different consumer groups for organic food. Second, cost-related factors have not been included in this study. There is little literature on the cost of promoting organic food behaviors through social media, and most of the literature on the price and behaviors is in the marketing research area. Therefore, we suggest that the follow-up study can be extended to examine how the cost and willingness to pay for organic food through social media affects the consumers' purchasing behavior.

\section{DATA AVAILABILITY STATEMENT}

The raw data supporting the conclusions of this article will be made available by the authors, without undue reservation.

\section{ETHICS STATEMENT}

Ethical review and approval was not required for the study on human participants in accordance with the local legislation and institutional requirements. Written informed consent from the patients/participants or patients/participants legal guardian/next of kin was not required to participate in this study in accordance with the national legislation and the institutional requirements.

\section{AUTHOR CONTRIBUTIONS}

J-JY and DJ developed the original idea for the study, contributed to research design, and performed the sample collection and data analysis. J-JY, DJ, and UW wrote the manuscript. All authors read and approved the final manuscript.

Benbrook, C. M., and Baker, B. P. (2014). Perspective on dietary risk assessment of pesticide residues in organic food. Sustainability 6, 3552-3570. doi: 10.3390/ su6063552

Bhattacherjee, A. (2001). Understanding information systems continuance: an expectation- confirmation model. MIS Q. 25, 351-370. doi: 10.2307/32 50921

Bhattacherjee, A., Perols, J., and Sanford, C. (2008). Information technology continuance: a theoretic extension and empirical test. J. Comput. Inf. Syst. 49, 17-26. doi: 10.1080/08874417.2008.11645302

Chang, H. H. (2010). Task-technology fit and user acceptance of online auction. Int. J. Hum. Comput. Stud. 68, 69-89. doi: 10.1016/j.ijhcs.2009.09.010

Chen, S. C., Liu, M. L., and Lin, C. P. (2013). Integrating technology readiness into the expectation-confirmation model: an empirical study of mobile services. Cyberpsychol. Behav. Soc. Netw. 16, 604-612. doi: 10.1089/cyber.2012.0606

Chen, S. C., Yen, D. C., and Hwang, M. I. (2012). Factors influencing the continuance intention to the usage of Web 2.0: an empirical study. Comput. Hum. Behav. 28, 933-941. doi: 10.1016/j.chb.2011.12.014 
Chen, S. C., Yen, D. C., and Peng, S. C. (2018). Assessing the impact of determinants in e-magazines acceptance: an empirical study. Comput. Stand. Interfaces 57, 49-58. doi: 10.1016/j.csi.2017.11.004

Cheng, Y. M. (2020). Will robo-advisors continue? Roles of task-technology fit, network externalities, gratifications and flow experience in facilitating continuance intention. Kybernetes doi: 10.1108/K-03-2020-0185 Online ahead of print,

Dabholkar, P. A., Shepherd, C. D., and Thorpe, D. I. (2000). A comprehensive framework for service quality: an investigation of critical conceptual and measurement issues through a longitudinal study. J. Retailing 76, 139-173. doi: 10.1016/s0022-4359(00)00029-4

Davis, F. D. (1989). Perceived usefulness, perceived ease of use, and user acceptance of information technology. MIS Q. 13, 319-340. doi: 10.2307/249008

Dishaw, M. T., and Strong, D. M. (1999). Extending the technology acceptance model with task-technology fit constructs. Inf. Manag. 36, 9-21. doi: 10.1016/ s0378-7206(98)00101-3

Fornell, C., and Larcker, D. F. (1981). Evaluating structural equation models with unobservables and measurement error. J. Mark. Res. 18, 39-50. doi: 10.2307/ 3151312

Goodhue, D. L., Klein, B. D., and March, S. T. (2000). User evaluations of IS as surrogates for objective performance. Inf. Manag. 38, 87-101. doi: 10.1016/ s0378-7206(00)00057-4

Goodhue, D. L., and Thompson, R. L. (1995). Task-technology fit and individual performance. MIS Q. 19, 213-236. doi: 10.2307/249689

Hair, J. F. Jr., Black, W. C., Babin, B. J., and Anderson, R. E. (2010). Multivariate Data Analysis: A Global Perspective, 7th Edn. Upper Saddle River, NJ: Pearson Education International.

Hair, J. F., Sarstedt, M., Ringle, C. M., and Mena, J. A. (2012). An assessment of the use of partial least squares structural equation modeling in marketing research. J Acad. Mark. Sci. 40, 414-433. doi: 10.1007/s11747-011-0261-6

Henseler, J., Ringle, C. M., and Sarstedt, M. (2015). A new criterion for assessing discriminant validity in variance-based structural equation modeling. J Acad. Mark. Sci. 43, 115-135. doi: 10.1007/s11747-014-0403-8

Janssen, M., and Hamm, U. (2012). Product labelling in the market for organic food: consumer preferences and willingness-to-pay for different organic certification logos. Food Q. Prefer. 25, 9-22. doi: 10.1016/j.foodqual.2011.12. 004

Khan, I. U., Hameed, Z., Yu, Y., Islam, T., Sheikh, Z., and Khan, S. U. (2018). Predicting the acceptance of MOOCs in a developing country: application of task-technology fit model, social motivation, and self-determination theory. Telematics Inform. 35, 964-978. doi: 10.1016/j.tele.2017.09.009

Kim, T., Suh, Y. K., Lee, G., and Choi, B. G. (2010). Modelling roles of tasktechnology fit and self-efficacy in hotel employees' usage behaviours of hotel information systems. Int. J. Tour. Res. 12, 709-725. doi: 10.1002/jtr.787

Klopping, I. M., and McKinney, E. (2004). Extending the technology acceptance model and the task-technology fit model to consumer e-commerce. Inf. Technol. Learn. Perform. J. 22, 35-48.

Larsen, T. J., Sørebø, A. M., and Sørebø, Ø (2009). The role of task-technology fit as users' motivation to continue information system use. Comput. Hum. Behav. 25, 778-784. doi: 10.1016/j.chb.2009.02.006

Lin, C. A., and Kim, T. (2016). Predicting user response to sponsored advertising on social media via the technology acceptance model. Comput. Hum. Behav. 64, 710-718. doi: 10.1016/j.chb.2016.07.027

Lin, C. S., Wu, S., and Tsai, R. J. (2005). Integrating perceived playfulness into expectation-confirmation model for web portal context. Inf. Manag. 42, 683693. doi: 10.1016/j.im.2004.04.003

Lin, W. S., and Wang, C. H. (2012). Antecedences to continued intentions of adopting e-learning system in blended learning instruction: a contingency framework based on models of information system success and task-technology fit. Comput. Educ. 58, 88-99. doi: 10.1016/j.compedu.2011.07.008

Lu, H. P., and Yang, Y. W. (2014). Toward an understanding of the behavioral intention to use a social networking site: an extension of task-technology fit to social-technology fit. Comput. Hum. Behav. 34, 323-332. doi: 10.1016/j.chb. 2013.10.020

Michaelidou, N., and Hassan, L. M. (2008). The role of health consciousness, food safety concern and ethical identity on attitudes and intentions towards organic food. Int. J. Consum. Stud. 32, 163-170. doi: 10.1111/j.1470-6431.2007.00619.x

Oghuma, A. P., Libaque-Saenz, C. F., Wong, S. F., and Chang, Y. (2016). An expectation-confirmation model of continuance intention to use mobile instant messaging. Telematics Inform. 33, 34-47. doi: 10.1016/j.tele.2015. 05.006

Oliver, R. L. (1993). Cognitive, affective, and attribute bases of the satisfaction response. J. Consum. Res. 20, 418-430. doi: 10.1086/209358

Oliver, R. L., and Richard, L. (1980). A cognitive model of the antecedents and consequences of satisfaction decision. J. Mark. Res. 17, 460-469. doi: 10.2307/ 3150499

Palen, L. (2008). Online social media in crisis events. Educause Q. 31, 76-78.

Park, E. (2020). User acceptance of smart wearable devices: an expectationconfirmation model approach. Telematics Inform. 47, 101318. doi: 10.1016/j. tele.2019.101318

Patterson, P. G., Johnson, L. W., and Spreng, R. A. (1997). Modeling the determinants of customer satisfaction for business-to-business professional services. J. Acad. Mark. Sci. 25, 4-17. doi: 10.1177/0092070397251002

Paul, J., and Rana, J. (2012). Consumer behavior and purchase intention for organic food. J. Consum. Mark. 29, 412-422. doi: 10.1108/07363761211259223

Rauniar, R., Rawski, G., Yang, J., and Johnson, B. (2014). Technology acceptance model (TAM) and social media usage: an empirical study on Facebook. J. Enterp. Inf. Manag. 27, 6-30. doi: 10.1108/jeim-04-2012-0011

Ringle, C. M., Sarstedt, M., and Straub, D. W. (2012). Editor's comments: a critical look at the use of PLS-SEM in". MIS Quarterly". MIS Q. 36, 3-14.

Roca, C. J., Chiu, C. M., and Martinez, F. J. (2006). Understanding e-learning continuance intention: an extension of the Technology Acceptance Model. Int. J. Hum. Comput. Stud. 64, 683-696. doi: 10.1016/j.ijhcs.2006.01.003

Ronald, P. C., and Adamchak, R. W. (2017). Tomorrow's Table: Organic Farming, Genetics, and the Future of Food. Oxford: Oxford University Press.

Schrier, T., Erdem, M., and Brewer, P. (2010). Merging task-technology fit and technology acceptance models to assess guest empowerment technology usage in hotels. J. Hosp. Tour. Technol. 1, 201-217. doi: 10.1108/17579881011078340

Singh, A., and Verma, P. (2017). Factors influencing Indian consumers' actual buying behaviour towards organic food products. J. Clean. Prod. 167, 473-483. doi: 10.1016/j.jclepro.2017.08.106

Tam, C., Santos, D., and Oliveira, T. (2020). Exploring the influential factors of continuance intention to use mobile Apps: extending the expectation confirmation model. Inf. Syst. Front. 22, 243-257. doi: 10.1007/S10796-0189864-5

Tse, D. K., and Wilton, P. C. (1988). Models of consumer satisfaction formation: an extension. J. Mark. Res. 25, 204-212. doi: 10.2307/3172652

Urbach, N., and Ahlemann, F. (2010). Structural equation modeling in information systems research using partial least squares. J. Inf. Technol. Theory Appl. 11, $5-40$.

Wamba, S. F., Bhattacharya, M., Trinchera, L., and Ngai, E. W. (2017). Role of intrinsic and extrinsic factors in user social media acceptance within workspace: assessing unobserved heterogeneity. Int. J. Inf. Manag. 37, 1-13. doi: 10.1016/j. ijinfomgt.2016.11.004

Wu, B., and Chen, X. (2017). Continuance intention to use MOOCs: integrating the technology acceptance model (TAM) and task technology fit (TTF) model. Comput. Hum. Behav. 67, 221-232. doi: 10.1016/j.chb.2016.10.028

Yen, D. C., Wu, C. S., Cheng, F. F., and Huang, Y. W. (2010). Determinants of users' intention to adopt wireless technology: an empirical study by integrating TTF with TAM. Comput. Hum. Behav. 26, 906-915. doi: 10.1016/j.chb.2010. 02.005

Yin, S., Wu, L., Du, L., and Chen, M. (2010). Consumers' purchase intention of organic food in China. J. Sci. Food Agric. 90, 1361-1367. doi: 10.1002/jsfa. 3936

Zhao, J., and Wang, J. (2020). Health advertising on short-video social media: a study on user attitudes based on the extended technology acceptance model. Int. J. Environ. Res. Public Health 17:1501. doi: 10.3390/ijerph17051501

Conflict of Interest: The authors declare that the research was conducted in the absence of any commercial or financial relationships that could be construed as a potential conflict of interest.

Copyright (C) 2020 You, Jong and Wiangin. This is an open-access article distributed under the terms of the Creative Commons Attribution License (CC BY). The use, distribution or reproduction in other forums is permitted, provided the original author(s) and the copyright owner(s) are credited and that the original publication in this journal is cited, in accordance with accepted academic practice. No use, distribution or reproduction is permitted which does not comply with these terms. 